\title{
ASSOCIATION BETWEEN OCCUPATIONAL LEAD EXPOSURE AND PLASMA LEVELS OF SELECTED OXIDATIVE STRESS RELATED PARAMETERS IN JORDANIAN AUTOMOBILE WORKERS
}

\section{ZIAD SHRAIDEH ${ }^{1}$, DARWISH BADRAN ${ }^{2}$, ABDELRAHIM HUNAITI ${ }^{3}$, and ABDELKADER BATTAH ${ }^{4}$}

The University of Jordan, Amman, Jordan

${ }^{1}$ Department of Biological Sciences, School of Science

${ }^{2}$ Department of Anatomy and Histology, School of Medicine

${ }^{3}$ Department of Clinical Laboratory Sciences, School of Science

${ }^{4}$ Department of Pathology, Microbiology and Forensic Medicine, School of Medicine

\begin{abstract}
Objectives: To study any possible correlation between blood lead levels and some oxidative stress parameters of selected groups of lead-exposed automobile occupational Jordanian workers. Material and Methods: Blood lead levels were determined for a total of 90 male automobile workers aged within the range of 25-45 years old along with the group of 20 agematched healthy males control. To get an idea about the antioxidant status of controls and lead-exposed workers, and to estimate the oxidative stress caused by exposure to lead, we measured the hydrogen peroxide $\left(\mathrm{H}_{2} \mathrm{O}_{2}\right)$ concentration, superoxide dismutase (SOD) activity, lipid peroxidation as malondialdehyde (MDA) and total antioxidant capacity of controls and workers. Results: The study showed that lead levels in the case of workers were approximately 4-5 times as high as in controls $14.5-21 \mu \mathrm{g} \times \mathrm{dl}^{-1} \mathrm{vs} .4 .3 \mu \mathrm{g} \times \mathrm{dl}^{-1}$, respectively. There was a significant decrease (16-25\%) in the level of plasma reduced glutathione and 21-33\% decrease in total antioxidant capacity (TAOC) in all worker groups, as compared to controls. The results showed that the concentration of malondialdehyde (MDA) in plasma was higher (120-333\%) in the case of workers than controls being the highest in automobile electronics and the lowest - in mechanics. Furthermore, there was 149-221\% increase in hydrogen peroxide $\left(\mathrm{H}_{2} \mathrm{O}_{2}\right)$ concentration, and 26-38\% increase in SOD activity in the case of workers compared to the control group. Conclusions: There is a strong evidence for the associations between occupational lead exposure and various markers of oxidative stress in Jordanian automobile occupational workers. Thus, there is an urgent need to raise awareness and to initiate suitable protection guidelines for workers. Int J Occup Med Environ Health 2018;31(4):517-525
\end{abstract}

Key words:

Cytotoxicity, Biomarkers, Oxidative stress, Exposure, Lead, Occupational health

Funding: this research was supported by Jordan Scientific Research Fund (grant No. MPH/2/2/2014 entitled "Cytotoxicity of lead emitted from automobile exhaust in selected Jordanian workers," grant manager: Prof. Ziad Shraideh).

Received: July 24, 2017. Accepted: October 5, 2017.

Corresponding author: Ziad Shraideh, The University of Jordan, Department of Biological Sciences, School of Science, Amman 11942, Jordan (e-mail: zshraideh@ju.edu.jo). 


\section{INTRODUCTION}

Lead is a highly toxic metal with adverse effects on human health and environment due to its widespread uses in many parts of the world. Work lead exposure is a common cause of lead toxicity in the case of adults with certain occupations deal with production, use, maintenance, recycling and disposal of lead products [1]. Several studies have associated lead exposure with a number of diseases including that of nervous, hematopoietic and reproductive system disease as well as kidney and bone diseases [1-3]. Various toxic effects induced by lead in biological systems have been linked to either or both the covalently interaction of lead $\left(\mathrm{Pb}^{2+}\right)$ with-sulfhydryl (SH) groups of the antioxidant defense system, which normally provide protection against free radical toxicity includes enzymes such as glutathione peroxidase (GPx), glutathione-S-transferase, superoxide dismutase (SOD), and catalase (CAT), and nonenzymatic molecule like glutathione (GSH) or by replacing the zinc ion which acts as an essential cofactor in their catalytic sites and inactivates them $[1,4]$.

Lead has also been shown to both elevate and suppress blood levels of the antioxidant enzymes superoxide dismutase (SOD), catalase, and glutathione peroxidase (GPx) [5-7]. Elevations of these enzymes have been seen in lower blood levels $(<40 \mu \mathrm{g} / \mathrm{dl})$. Furthermore, $\mathrm{Pb}^{2+}$ effect may be seen in the increased production of reactive oxygen species (ROS) by accelerating of oxidation of oxyhaemoglobin to methaemoglobin and thus induces oxidative stress by generating imbalance between production of free radicals in tissues and cellular components and their ability to detoxify the extremely reactive intermediates that causing damage to membranes, DNA and proteins [1].

Glutathione is a tripeptide composed of L- $\gamma$-glutamylcysteinyl-glycine, makes up $90 \%$ of the overall non-protein thiol of the cell and is considered as the mother of antioxidants that protects cells from oxidative and peroxida- tive damage. Reduction in GSH levels during lead toxicity has been reported in many studies [5,8,9]. In our early study [10] we found correlation between depressed GSH levels and depressed levels of glutathione reductase, glutathione peroxidase, and glutathione-S-transferase in occupationally lead-exposed workers. Sugawara et al. [5] reported that the decreased level of GSH and decreased activity of SOD, CAT and GPx in erythrocytes from workers exposed to lead may play a part in the increased membrane lipid peroxidation.

Systematic studies on lead-induced oxidative stress have been based mostly on in vitro experiments [1,8,11]. Lead may directly be attached to a cell membrane, thus increasing the sensitivity of the membrane to the process of lipid peroxidation [1]. Malondialdehyde (MDA) is the final product in the lipid peroxidation process, and may be used as a good biomarker for membrane lipid peroxidation. Evaluating oxidative stress biomarkers of lead exposure and establishing diagnosis and initiate more suitable monitory systems are very crucial for the protection of lead-exposed workers against lead intoxication. The article presents evidences on the association of oxidative stress with exposure to lead among 6 groups of automobile workers in Jordan.

\section{MATERIAL AND METHODS}

\section{Study population}

A total of 90 male volunteers - Jordanian automobile workers in Amman City were involved in this study. The study group subjects were further divided into 6 groups (15 each) depending upon the type of work to include: radiator welders, exhaust workers, automobile electronics, car painters, car mechanics and metal workers. The control group (20 healthy volunteers) members were selected from the same locality and were matched for age, sex, and dietary habits. Only those who proved to be in a good state of health and free from any sign/s of chronic disease/s or disorder/s were included. None of them was exposed to 
any occupational exposure to lead. For the study, the ethical clearance was obtained from the University of Jordan Hospital Ethical Committee and a written consent was obtained from all subjects, who had been informed of the importance of the study.

\section{Blood collection}

Blood samples were collected from the subjects under aseptic condition. Six milliliters of total venous blood from each subject in dipotassium ethylenediaminetetraacetic acid (EDTA) vacutainers was used for estimating lead concentration. Another $6 \mathrm{ml}$-sized blood sample was obtained in plane tubes (vacutainer). The tubes were centrifuged at $3000 \mathrm{rpm}$ for $10 \mathrm{~min}$ at room temperature to separate plasma and red blood cells. All the samples were analyzed on the same day of collection. Plasma was used for determining the activity of superoxide dismutase (SOD) and reduced glutathione $(\mathrm{GSH}), \mathrm{H}_{2} \mathrm{O}_{2}$ concentration, in addition to total antioxidant capacity and lipid peroxidation (MDA).

\section{Analytical methods}

Blood lead

Blood lead levels were determined as per the method given by Palmer et al. [12]. Using a graphite furnace atomic absorption spectrophotometer and blood lead contents were expressed as $\mu \mathrm{g} / \mathrm{dl}$.

\section{Reduced glutathione}

The kinetic assay in which catalytic amounts (nmoles) of GSH cause a continuous reduction of 5,5'-dithiobis (2-nitrobenzoic acid) (DTNB) to 5-thio-2-nitrobenzoic acid (TNB) and the glutathione disulfide (GSSG) formed is recycled by glutathione reductase and nicotinamide adenine dinucleotide phosphate (NADPH) was used for GSH determination according to the manufacturing instructions (Glutathione Assay Kit No. 703002, Cayman Chemical, Ann Arbor, USA).
$\mathrm{H}_{2} \mathrm{O}_{2}$ concentration

To measure $\mathrm{H}_{2} \mathrm{O}_{2}$ concentration in blood samples, we used: Hydrogen Peroxide Assay Kit (No. ab102500) manufactured by ABCAM according to manufacturer's instructions and the results were expressed as $\mu \mathrm{mole} / \mathrm{l}$.

\section{Lipid peroxidation (concentration of MDA)}

Determination of lipid peroxidation levels in serum samples were measured using the thiobarbituric acid reaction method of Draper and Hadley [13]. Malondialdehyde levels were estimated by the thiobarbituric acid reactivity to generate a MDA2-thiobarbituric acid (TBA) adduct which may be easily quantified colormetrically at $532 \mathrm{~nm}$. Using a Bio Assay Systems kit colorimetric assay to measure $\mathrm{H}_{2} \mathrm{O}_{2}$ concentration in blood samples, we used Hydrogen Peroxide Assay Kit (No. ab102500) manufactured by ABCAM according to manufacturer's instructions and the results were expressed as $\mu$ mole/l.

\section{Total antioxidant capacity}

The TAC in serum samples was measured using Randox kit NX2615 (Randox Laboratories, Crumlin, UK) according to the manufacturing instruction.

\section{Superoxide dismutase (SOD) activity}

Superoxide dismutase activity is measured as the inhibition of the rate of reduction of cytochrome $\mathrm{c}$ by the superoxide radical, observed at $550 \mathrm{~nm}$ essentially as described by Beckman et al. [14]. Superoxide dismutase activity is expressed as $\mathrm{U} / \mathrm{l}$.

\section{Statistical analysis}

The statistical analysis was conducted using SAS v. 9 (SAS Institute, 2002). Data was evaluated using PROC GLM, in SAS. The model included the effects of treatment (D4 vs. D6 vs. control), parity (primiparous vs. multiparous), season (summer vs. winter), and their interactions. Values were expressed as means $(\mathrm{M}) \pm$ standard error (SE). Results were expressed as specific units or as a number. 
Least square means for significant effects were compared at $\mathrm{p}<0.05$ using t-test.

To find the correlation between age, work duration, lead concentration and other studied parameters, all workers were classified into 4 age groups:

- group 1 - 25-30 years old,

- group 2-31-35 years old,

- group 3-36-40 years old,

- group 4-41-45 years old.

Work duration, lead concentration was analyzed for every age group.

The correlation coefficient analysis was also done.

\section{RESULTS}

A total of 90 automobile male workers in Amman City, Jordan were selected to include:

- group A - 15 radiator welders,

- group B - 15 exhaust workers,

- group C-15 automobile electronics,

- group D - 15 car painters,

- group E-15 car mechanics,

- group F-15 car metal workers.
The characteristics of the study participants are summarized in the Table 1 . Subjects ranged from 25 to 45 years of age. The time of work duration for the automobile-related job for participants ranged 6.4-28.3 years (Table 1). The control group consisted of 20 age-matched healthy males who were exposed to lead only environmentally and did not carry out any activities associated with lead products preparation or handling.

The statistical analysis of work duration among the 4 age groups showed that workers of group 1 (age: 25-30 years old) have work duration of $6.4 \pm 2.4$ years $(\mathrm{M} \pm \mathrm{SE})$, group 2 (age: $31-35$ years old) have work duration of $11.4 \pm 1.5$ years $(\mathrm{M} \pm \mathrm{SE}$ ), group 3 (age: 36-40 years old) have work duration of $21.5 \pm 1.7$ years $(\mathrm{M} \pm \mathrm{SE}$ ), while group 4 (age: $41-45$ years old) have work duration of $28.3 \pm 1.8$ years $(\mathrm{M} \pm \mathrm{SE})$.

\section{Blood lead levels}

Blood lead levels were significantly higher in all worker groups (range: $14.5-21 / \mu \mathrm{g} \times \mathrm{dl}^{-1}$ ) as compared to controls $\left(\mathrm{M} \pm \mathrm{SE}=4.3 \pm 0.5 / \mu \mathrm{g} \times \mathrm{dl}^{-1}\right)$. The highest level was reported for automobile electronics and the lowest was for radiator welders (Table 2), while car painters, me-

Table 1. Characteristics of the study participants - lead-exposed automobile workers and control group, Jordan

\begin{tabular}{lccccc}
\hline \multirow{1}{*}{$\begin{array}{l}\text { Group } \\
\text { Workers }\end{array}$} & \multicolumn{2}{c}{$\begin{array}{c}\text { Seniority } \\
\text { [years] }\end{array}$} & \multicolumn{2}{c}{$\begin{array}{c}\text { Age } \\
\text { [years] }\end{array}$} \\
\cline { 3 - 6 } & & range & M \pm SE & range & M \pm SE \\
\hline Study group & 15 & & & & \\
$\quad$ radiator welders & 15 & $16-33$ & $19.0 \pm 2.0$ & $25-44$ & $35.0 \pm 1.0$ \\
exhaust workers & 15 & $7-32$ & $20.0 \pm 1.7$ & $25-45$ & $35.0 \pm 0.8$ \\
automobile electronics & 15 & $6-25$ & $25.0 \pm 2.3$ & $23-43$ & $36.0 \pm 1.2$ \\
car painters & 15 & $5-25$ & $19.0 \pm 1.8$ & $25-44$ & $35.0 \pm 0.9$ \\
car mechanics & 15 & $15-30$ & $17.0 \pm 2.4$ & $30-45$ & $36.0 \pm 1.2$ \\
car metal workers & 90 & $8-30$ & $15.0 \pm 2.3$ & $25-45$ & $34.0 \pm 1.2$ \\
total & 20 & $6.4-28.3$ & $17.1 \pm 1.8$ & $25-45$ & $34.9 \pm 0.9$ \\
Control group & & 0 & 0 & $25-45$ & $34.0 \pm 3.0$ \\
\hline
\end{tabular}

M - mean; SE - standard error. 
chanics and metal workers (groups D-F) showed similar blood lead levels. Blood lead increased significantly by $337-448 \%$ in all groups compared to the control group. Blood lead levels were variable among the 6 work groups; being the highest in work group $\mathrm{C}$ which has lead blood levels $21 \pm 1.6 \mu \mathrm{g} \times \mathrm{dl}^{-1}(\mathrm{M} \pm \mathrm{SE})$, followed by group B which has blood level 16.4 $\pm 1.2 \mu \mathrm{g} \times \mathrm{dl}^{-1}(\mathrm{M} \pm \mathrm{SE})$. Worker group A showed the lowest blood lead level $\left(\mathrm{M} \pm \mathrm{SE}=14.5 \pm 1.4 \mu \mathrm{g} \times \mathrm{dl}^{-1}\right)$.

The statistical analysis and correlation coefficient between $\mathrm{Pb}$ concentration and years of duration in the case of exposed workers have been calculated for the 4 age groups. Results showed that workers of group 1 (25-30 years) had the blood lead concentration of $13.8 \pm 1.7 \mu \mathrm{g} \times \mathrm{dl}^{-1}(\mathrm{M} \pm \mathrm{SE})$, group 2 had blood lead concentration of $12.7 \pm 1.1 \mu \mathrm{g} \times \mathrm{dl}^{-1}(\mathrm{M} \pm \mathrm{SE})$, group $3 \mathrm{had}$ blood lead concentration of $15.4 \pm 1.2 \mu \mathrm{g} \times \mathrm{dl}^{-1}(\mathrm{M} \pm \mathrm{SE})$, while group 4 had blood lead concentration of $16.1 \pm 1.3 \mu \mathrm{g} \times \mathrm{dl}^{-1}(\mathrm{M} \pm \mathrm{SE})$.

\section{Biomarkers of oxidative stress and antioxidants}

In order to assess the oxidative stress (OS) caused by exposure to lead, we measured the typical OS and antioxidant biomarkers and the ratio between oxidant (MDA) and antioxidants (GSH and SOD). The Table 2 shows the results obtained in blood samples of the study groups and control ones. When levels of MDA in plasma were measured as one of the most popular biomarker of lipid peroxidation, the serum lipid peroxide level of workers groups ( $\mathrm{N}=90$ ) was found to be in the range of $3.6 \pm 0.3 \mu \mathrm{mole} / \mathrm{l}$ to $9 \pm 0.8 \mu$ mole/l $(\mathrm{M} \pm \mathrm{SE})$ whereas that of the control group $(\mathrm{N}=20)$ was $3 \pm 0.2 \mu$ mole $/ 1(\mathrm{M} \pm \mathrm{SE})$ of MDA. This means that plasma MDA levels were significantly increased by $120 \pm 16 \%$ to $333 \pm 83 \%$ ( $\mathrm{M} \pm \mathrm{SE}$ ) in worker groups as compared to the control group (Table 2). Accordingly, there were significant differences between worker groups (range (M $\pm \mathrm{SE}): 8.9 \pm 0.2-13.3 \pm 0.3 \mu \mathrm{mole} / \mathrm{l})$ and the control group $\left(6 \pm 1 \mu\right.$ mole/l) when $\mathrm{H}_{2} \mathrm{O}_{2}$ concentrations were measured (Table 2).

Table 2. Blood lead levels in relation to chosen biochemical parameters in lead-exposed automobile workers and control group, Jordan

\begin{tabular}{|c|c|c|c|c|c|c|c|c|}
\hline Group & $\begin{array}{c}\text { Lead } \\
\text { concentration } \\
{[\mu \mathrm{g} / \mathrm{dl}]} \\
(\mathrm{M} \pm \mathrm{SE})\end{array}$ & $\begin{array}{c}\mathrm{GSH} \\
\text { concentration } \\
{[\mu \mathrm{mole} / \mathrm{l}]} \\
(\mathrm{M} \pm \mathrm{SE})\end{array}$ & $\begin{array}{c}\text { SOD } \\
\text { activity } \\
{[\mathrm{U} / \mathrm{l}]} \\
(\mathrm{M} \pm \mathrm{SE})\end{array}$ & $\begin{array}{c}\text { Lipid } \\
\text { peroxidation } \\
(\mathrm{MDA} \\
\text { concentration }) \\
{[\mu \mathrm{mole} / \mathrm{l}]} \\
(\mathrm{M} \pm \mathrm{SE})\end{array}$ & $\begin{array}{c}\mathrm{H}_{2} \mathrm{O}_{2} \\
\text { concentration } \\
{[\mu \mathrm{mole} / \mathrm{l}]} \\
(\mathrm{M} \pm \mathrm{SE})\end{array}$ & $\begin{array}{c}\text { TAOC } \\
{[\mu \mathrm{mole} / \mathrm{ml}]} \\
(\mathrm{M} \pm \mathrm{SE})\end{array}$ & $\begin{array}{c}\text { MDA/ } \\
\text { GSH }\end{array}$ & $\begin{array}{c}\text { MDA/ } \\
\text { SOD }\end{array}$ \\
\hline \multicolumn{9}{|l|}{ Study group } \\
\hline radiator welders & $14.5 \pm 1.4$ & $446.6 \pm 6.0$ & $3.7 \pm 0.3$ & $4.4 \pm 0.3$ & $11.4 \pm 0.2$ & $0.08 \pm 0.01$ & 2.0 & 1.19 \\
\hline exhaust workers & $16.4 \pm 1.2$ & $452.0 \pm 7.0$ & $3.6 \pm 0.3$ & $3.9 \pm 0.3$ & $10.3 \pm 0.2$ & $0.07 \pm 0.01$ & 2.0 & 1.08 \\
\hline $\begin{array}{l}\text { automobile } \\
\text { electronics }\end{array}$ & $21.0 \pm 1.6$ & $435.0 \pm 6.0$ & $3.4 \pm 0.2$ & $9.0 \pm 0.8$ & $13.3 \pm 0.3$ & $0.07 \pm 0.01$ & 4.0 & 2.64 \\
\hline car painters & $15.0 \pm 1.3$ & $435.0 \pm 5.0$ & $3.7 \pm 0.3$ & $4.6 \pm 0.3$ & $10.7 \pm 0.2$ & $0.08 \pm 0.01$ & 2.0 & 1.24 \\
\hline car mechanics & $15.0 \pm 1.7$ & $487.0 \pm 6.0$ & $3.4 \pm 0.2$ & $3.6 \pm 0.3$ & $10.9 \pm 0.2$ & $0.07 \pm 0.01$ & 1.4 & 1.06 \\
\hline car metal workers & $15.0 \pm 1.6$ & $481.0 \pm 7.0$ & $3.3 \pm 0.2$ & $7.7 \pm 0.6$ & $8.9 \pm 0.2$ & $0.07 \pm 0.01$ & 4.0 & 2.33 \\
\hline Control group & $4.3 \pm 0.5$ & $580.0 \pm 8.0$ & $2.7 \pm 0.2$ & $3.0 \pm 0.2$ & $6.0 \pm 1.0$ & $0.10 \pm 0.01$ & 1.0 & 1.11 \\
\hline
\end{tabular}

$\mathrm{M}$ - mean; SE - standard error.

GSH - reduced glutathione; SOD - superoxide dismutase; MDA - malondialdehyde; $\mathrm{H}_{2} \mathrm{O}_{2}$ - hydrogen peroxide; TAOC - total antioxidant capacity. 
The highest $\mathrm{H}_{2} \mathrm{O}_{2}$ concentration $(\mathrm{M} \pm \mathrm{SE}=13.3 \pm 0.3 \mu$ mole/l $)$ was reported in group $\mathrm{C}$ (automobile electronics) (Table 2).

To gain more information about the redox status in the study group we evaluated the antioxidant capacity in these groups. The results of antioxidant status were also significantly changed (Table 2). Superoxide dismutase activity was slightly increased in all worker groups (range $(\mathrm{M} \pm \mathrm{SE}): 3.3 \pm 0.2-3.7 \pm 0.3 \mathrm{U} / 1)$, compared to the control group $(\mathrm{M} \pm \mathrm{SE}=2.7 \pm 0.2 \mathrm{U} / \mathrm{l})$ (Table 2). The highest increase in SOD activity was found in groups $A$ and $D$ $(\mathrm{M} \pm \mathrm{SE}=37.4 \pm 1.6 \%)$ as compared to the control group. A marked decrease in the levels of GSH was observed in all worker groups (range $(\mathrm{M} \pm \mathrm{SE})$ : $435 \pm 5-487 \pm 6 \mu$ mole/l) compared to the control group $(\mathrm{M} \pm \mathrm{SE}=580 \pm 8 \mu \mathrm{mole} / \mathrm{l})$ (Table 2). The decrease of $25 \%$ in GSH occurred in both $\mathrm{C}$ and $\mathrm{D}$ groups while groups $\mathrm{E}$ and $\mathrm{F}$ were the least affected (16\% and 17\%) (Table 2). Accordingly, the values of total antioxidant capacity (TAOC) were decreased by $20 \%$ to $30 \%$ in all worker groups (range $(\mathrm{M} \pm \mathrm{SE}): 0.07 \pm 0.01-0.08 \pm 0.01 \mu \mathrm{mole} / \mathrm{ml})$ compared to the control group $(0.1 \pm 0.01 \mu$ mole $/ \mathrm{ml})$ (Table 2$)$.

The ratios of oxidant as measured by the level of MDA to antioxidants as represented by GSH and SOD levels were used as an oxidative stress index. The increase in the ratio of MDA/GSH was seen in all worker groups. The 4-fold increase was observed in group $\mathrm{C}$ and $\mathrm{F}$ compared to the control group. Accordingly, a double increase in the ratio of MDA/SOD was reported only in group $\mathrm{C}$ and $\mathrm{F}$ (Table 2).

\section{DISCUSSION}

Lead occupational exposure is common among automobile workers [15] especially in developing countries because of the lack of regulation for setting a reference blood level for workers. While in the USA, for example, the National Institute for Occupational Safety and Health (NIOSH) regulation in 2015 designated $5 \mu \mathrm{g} / \mathrm{dl}$ of whole blood in a venous blood sample as the refer- ence blood level for adults while elevated blood lead levels (BLL) are defined as $\geq 5 \mu \mathrm{g} / \mathrm{dl}$ [16]. According to this classification, the results of our study clearly demonstrate that automobile workers have higher blood lead levels than controls and that all the included 6 groups of automobile workers had elevated blood lead levels. Our study is in agreement with other previous reports on blood lead levels in Jordan [10].

The mean blood lead levels of the exposed workers involved in various automobile job categories were in the range between $14.5 \pm 1.4$ and $21 \pm 1.6 \mu \mathrm{g} / \mathrm{dl}$. The workers involved in automobile electronics had a higher mean blood lead of $21 \pm 1.6 \mu \mathrm{g} / \mathrm{dl}$ than those of other groups. The blood lead levels reported in this study for radiator welders and metal casters are lower than those previously reported in Irbid City by Hunaiti et al. [10] $(32.8 \mu \mathrm{g} / \mathrm{dl}$ vs. $14.5 \mu \mathrm{g} / \mathrm{dl}$ for radiator welders and $41.6 \mu \mathrm{g} / \mathrm{dl}$ vs. $15.5 \mu \mathrm{g} / \mathrm{dl}$ for metal casters, respectively) while for car painters and car mechanics, they are higher $(10.7 \mu \mathrm{g} / \mathrm{dl}$ vs. $15 \mu \mathrm{g} / \mathrm{dl}$ and $8.1 \mu \mathrm{g} / \mathrm{dl}$ vs. $15 \mu \mathrm{g} / \mathrm{dl}$ ), respectively. The observed differences could be due to public awareness since the blood levels of control groups dropped from $5.7 \mu \mathrm{g} / \mathrm{dl}$ in 1995 study to $4.3 \mu \mathrm{g} / \mathrm{dl}$ in this study or to differences in the 2 cities location and population.

Despite this drop, the blood levels in all worker groups are still elevated and higher than the results of the study performed by a group of researchers from the Ministry of Health and the Royal Medical Services to determine the blood lead level in the non-occupationally exposed Jordanian population [17]. In this study, 764 blood samples were collected and analyzed, and the sample taken was a representative sample for the Jordanian community and there was no statistically significant difference between male and female blood lead levels [17]. The arithmetic mean for blood lead level in the whole sample was $2.18 \mu \mathrm{g} / \mathrm{dl}$ which is lower than our control group value $(4.3 \mu \mathrm{g} / \mathrm{dl})$ and close to the average "reference value" for blood lead concentrations among Korean adolescents $22.5 \mu \mathrm{g} / \mathrm{l}(24.9 \mu \mathrm{g} / \mathrm{l}$ 
for males, $20.7 \mu \mathrm{g} / \mathrm{l}$ for females), and the geometric mean of the blood lead concentrations was $13.4 \mu \mathrm{g} / \mathrm{l}$ [18].

Moreover our control group lead level is similar to that reported in China, where median levels of blood lead levels in the male and female population aged $0-18$ years old were $48.8 \mu \mathrm{g} / \mathrm{dl}$ and $46.1 \mu \mathrm{g} / \mathrm{dl}$, respectively [19]. Similarly, in the United States, the average blood lead concentrations were $22.8 \mu \mathrm{g} / \mathrm{dl}, 45.5 \mu \mathrm{g} / \mathrm{dl}$, and $40.7 \mu \mathrm{g} / \mathrm{dl}$ for Caucasian, black, and Hispanic and Mexican American adolescents, respectively [20]. Biomonitoring studies on levels of lead and associated biomarkers provide public health officials with reference values so that they can determine whether people have been exposed to higher levels of lead than are found in the general population.

The correlation coefficient analysis of blood lead concentration for the workers of the 4 age groups, showed a positive correlation, which means accumulation of lead in the body with time. Age group 4 (41-45 years) had the highest mean blood lead concentration $(16.1 \mu \mathrm{g} / \mathrm{dl})$, compared to group 1 (25-30 years) and group 2 (31-35 years) with blood lead means of $13.8 \mu \mathrm{g} / \mathrm{dl}$ and $12.7 \mu \mathrm{g} / \mathrm{dl}$, respectively.

The correlation analysis between blood lead concentration and biomarkers of oxidative stress and antioxidants, showed a positive correlation in all studied worker groups. Biomonitoring studies on levels of lead and associated biomarkers provide public health officials with reference values so that they can determine whether people have been exposed to higher levels of lead than are found in the general population. Therefore in this study we aimed to specifically investigate if elevated occupational exposure to lead in automobile workers was associated with increased incidence of oxidative stress which was a significant contributor to various pathophysiological processes $[1,4]$.

It is known that oxidative stress is caused by either increase production of reactive oxygen or nitrogen species or decrease antioxidant defenses or both. Several studies support the role of oxidative stress in the pathophysiology of lead toxicity $[1,4,21,22]$. The biological mechanisms behind $\mathrm{Pb}$-induced oxidative stress have been reviewed by Ahamed and Siddiqui [4]. These mechanisms include the inhibiting of the enzymes involved in the heme biosynthetic pathway and thereby generating free radicals, increasing the susceptibility of cell-membrane to peroxidation, depleting glutathione (GSH) and changing the activities of the antioxidant enzymes. Our results showed that, exposure to elevated lead levels caused a significant increase in $\mathrm{H}_{2} \mathrm{O}_{2}$ concentration, SOD activity and the lipid peroxidation biomarker (MDA) in worker groups compared to controls.

Similar findings were shown by Kasperczyk et al. [23]. They indicate a significant increase (48\%) in erythrocyte MDA level in zinc and lead manufacturing workers exposed to lead for an average of 16.6 years and have a mean blood lead levels $40.53 \mu \mathrm{g} / \mathrm{dl}$ in the southern region of Poland. Chronic exposure of lead in battery manufacturing workers of western Maharashtra India showed a decrease activities of SOD and catalase which associated with increased lipid peroxidation [24,25]. Exposure to lead gives rise to a high production of reactive oxygen species; especially $\mathrm{H}_{2} \mathrm{O}_{2}$. Our findings support this notion. The increase in $\mathrm{H}_{2} \mathrm{O}_{2}$ concentrations was found in all groups of lead-exposed workers compared to the control group. There was a statically significant increase in the levels of SOD in all worker groups compared to the control group. The increase in SOD activity observed in this study supports the concept of possible systemic oxidative stress in occupationally lead-exposed toxicity.

Flora et al. [1] reported that toxicity of lead was associated with changes in enzymatic and non-enzymatic antioxidant mechanisms. Depleting of GSH and changing the activities of the antioxidant enzymes are frequently observed in the case of workers occupationally exposed to lead $[4,10]$. Our results showed a 16-25\% decrease in GSH levels in all worker groups compared to the control group. The decrease in GSH levels in lead-exposed workers observed in this study could be due to the fact that the affinity of lead 
towards sulfhydryl groups (-SH) makes GSH more susceptible to binding with lead, which may cause a marked decrease in GSH levels [1,4]. Accordingly, the values of TAOC were decreased by $20-30 \%$ in all worker groups compared to the control group. Disturbances in the normal redox state of cells by decreasing the levels of enzymatic and non-enzymatic antioxidants and increasing of lipid peroxidation may cause toxic effects and might be the cause of reduced ability of plasma to withstand oxidative stress induced by lead which is perceived as diminished TAOC among automobile workers in Jordan. Moreover, in most of the cases we noticed that as duration of exposure/work duration was increased, the effect was enhanced.

\section{CONCLUSIONS}

The observed correlation between blood lead levels and the studied oxidative stress and antioxidant parameters suggests that lead may have induced oxidative damage to automobile workers by generating free radicals and lipid peroxidation and impaired their enzymatic and non-enzymatic antioxidants defenses, and this damage was enhanced as duration of exposure/work duration was increased. Therefore, analyses of oxidative-stress and antioxidant-related parameters in lead-exposed workers are important in evaluating the health effects and biomarker of lead exposure and establishing a better diagnosis and prevention standards.

\section{REFERENCES}

1. Flora G, Gupta D, Tiwari A. Toxicity of lead: A review with recent updates. Interdiscip Toxicol. 2012;5(2):47-58, https:// doi.org/10.2478/v10102-012-0009-2.

2. Patrick L. Lead toxicity part II: The role of free radical damage and the use of antioxidants in the pathology and treatment of lead toxicity. Altern Med Rev. 2006;11(2):114-27.

3. Carocci A, Catalano A, Lauria G, Sinicropi MS, Genchi G. Lead toxicity, antioxidant defense and environment. Rev Environ Contam Toxicol. 2016;238:45-67, https:/doi.org/ $10.1007 / 398$ 2015_5003.
4. Ahamed M, Siddiqui MKJ. Low level lead exposure and oxidative stress: Current opinions. Clin Chim Acta. 2007; 383(1-2):57-64, https://doi.org/10.1016/j.cca.2007.04.024.

5. Sugawara E, Nakamura K, Miyake T, Fukumura A, Seki Y. Lipid peroxidation and concentration of glutathione in erythrocytes from workers exposed to lead. Br J Ind Med. 1991;48(4):239-42, https://doi.org/10.1136/oem.48.4.239.

6. Chiba M, Shinohara A, Matsushita K, Watanabe H, Inaba Y. Indices of lead-exposure in blood and urine of lead-exposed workers and concentrations of major and trace elements and activities of SOD, GSHPx and catalase in their blood. Tohoku J Exp Med. 1996;178(1):49-62, https://doi.org/10.1620/ tjem.178.49.

7. Han SG, Kim Y, Kashon ML, Pack DL, Castranova V, Vallyathan V. Correlates of oxidative stress and free-radical activity in serum from asymptomatic shipyard welders. Am J Respir Crit Care Med. 2005;172(12):1541-8, https://doi. org/10.1164/rccm.200409-12220C.

8. Hunaiti AA, Soud MO. Effect of lead concentration on the level of glutathione, glutathione S-transferase, reductase and peroxidase in human blood. Sci Total Environ. 2000;248(1):45-50, https://doi.org/10.1016/S0048-9697 (99)00548-3.

9. Jangid AP, Shekhawat VP, Pareek H, Yadav D, Sharma P, John PJ. Effect of lead on human blood antioxidant enzymes and glutathione. Int J Biochem Res Rev. 2016;13(1):1-9.

10. Hunaiti A, Soud M, Khalil A. Lead concentration and the level of glutathione, glutathione transferase, reductase and peroxidase in the blood of some occupational workers from Irbid City, Jordan. Sci Total Environ. 1995;170(1-2):95-100, https://doi.org/10.1016/0048-9697(95)04606-2.

11. Ding Y, Gonic HC, Vaziri ND. Lead promotes hydroxyl radical generation and lipid peroxidation in cultured aortic endothelial cells. Am J Hypertens. 2000;13(5 Pt 1):552-5, https://doi.org/10.1016/S0895-7061(99)00226-5.

12. Palmer CD, Lewis ME, Geraghty CM, Barbosa F, Parsons PJ. Determination of lead, cadmium and mercury in blood for assessment of environmental exposure: 
A comparison between inductively coupled plasma-mass spectrometry and atomic absorption spectrometry. Spectrochimica Acta Part B At Spectrosc. 2006;61(8):980-90, https://doi.org/10.1016/j.sab.2006.09.001.

13. Draper HH, Hadley M. Malondialdehyde determination as index of lipid peroxidation. Methods Enzymol. 1990;186: 421-31, https://doi.org/10.1016/0076-6879(90)86135-I.

14. Beckman JS, Beckman TW, Chen J, Marshall PA, Freeman BA. Apparent hydroxyl radical production by peroxynitrite: Implications for endothelial injury from nitric oxide and superoxide. Proc Natl Acad Sci U.S.A. 1990;87(4):1620-4.

15. Barman T, Kalahasthi R, Rajmohan HR. Effects of lead exposure on the status of platelet indices in workers involved in a lead-acid battery manufacturing plant. J Expo Sci Environ Epidemiol. 2014;24(6):629-33, https://doi.org/10.1038/ jes.2014.4.

16. Gurer-Orhan H, Sabir HU, Ozgüneş H. Correlation between clinical indicators of lead poisoning and oxidative stress parameters in controls and lead-exposed workers. Toxicology. 2004;195(2-3):147-54, https://doi.org/10.1016/ j.tox.2003.09.009.

17. Ministry of Health [Internet]. Amman: The Ministry [cited 2017 Jul 24]. Health research. Available from: http://apps. moh.gov.jo/MOH/En/health_researchdetails_thi.php?re searchid $=35$.

18. Choi MG, Park MJ, Kim SH. Reference values of lead in blood and related factors among Korean adolescents: The Korean National Health and Nutrition Examination Survey 2010-2013. Korean J Pediatr. 2016;59(3):114-9, https:// doi.org/10.3345/kjp.2016.59.3.114.

19. Li MM, Cao J, Xu J, Cai SZ, Shen XM, Yan CH. The national trend of blood lead levels among Chinese children aged 0-18 years old, 1990-2012. Environ Int. 2014;71: 109-17, https://doi.org/10.1016/j.envint.2014.06.005.

20. White BM, Bonilha HS, Ellis C Jr. Racial/ethnic differences in childhood blood lead levels among children $<72$ months of age in the United States: A systematic review of the literature. J Racial Ethn Health Disparities. 2016;3(1):145-53, https://doi.org/10.1007/s40615-015-0124-9.

21. Saliu A, Adebayo O, Kofoworola O, Babatunde O, Ismail A. Comparative assessment of blood levels of automobile technicians in organized and roadside garages in Lagos, Nigeria. J Environ Public Health. 2015;2015:976563, https://doi. org $/ 10.1155 / 2015 / 976563$.

22. Centers for Disease Control and Prevention, National Institute of Occupational Safety and Health [Internet]. Atlanta: The Centers; 2017 [cited 2017 Jul 24]. Adult Blood Lead Epidemiology and Surveillance (ABLES). Program Description 2015. Available from: http://www.cdc.gov/niosh/topics/ ables/description.html.

23. Kasperczyk A, Słowińska-Łożyńska L, Dobrakowski M, Zalejska-Fiolka J, Kasperczyk S. The effect of lead-induced oxidative stress on blood viscosity and rheological properties of erythrocytes in lead exposed humans. Clin Hemorheol Microcirc. 2014;56(3):187-95, https://doi.org/10.3233/CH131678.

24. Mudipalli A. Lead hepatotoxicity \& potential health effects. Indian J Med Res. 2007;126(6):518-27.

25. Patil AJ, Bhagwat VR, Patil JA, Dongree NN, Ambekar JG, Jailkhani $\mathrm{R}$, et al. Effect of lead $(\mathrm{Pb})$ exposure on the activity of superoxide dismutase and catalase in battery manufacturing workers (BMW) of Western Maharashtra (India) with reference to heme biosynthesis. Int J Environ Res Public Health. 2006;3(4):329-78.

This work is available in Open Access model and licensed under a Creative Commons Attribution-NonCommercial 3.0 Poland License - http://creativecommons.org/ licenses/by-nc/3.0/pl/deed.en. 